\title{
Stature Reconstruction from Measurements of Craniofacial Parameters: A Study of the Oro People of Akwa Ibom State
}

\author{
Iboro E. Edet, Akpan U. Ekanem, Sunday O. Elijah, Kingsley A. Okon, and Mfonobong E. Sampson \\ Department of Anatomy, Faculty of Basic Medical Sciences, University of Uyo, Akwa Ibom State - Nigeria \\ DOI: https://dx.doi.org/10.51584/IJRIAS.2021.6405
}

\begin{abstract}
Stature prediction from craniofacial remains is vital in establishing the identity of an unknown individual in cases of natural calamities and archaeological exploration where complete skeleton is not available. This study aims to estimate stature among the Oro ethnic group in Akwa Ibom State using craniofacial parameters, hence determine the craniofacial parameter that best predict stature for the Oro people and therefore document a model formulae for stature prediction using Poisson regression analysis. The study assessed 500 subjects (245 males and 255 females) between the ages 18 - 77, with no craniofacial nor stature abnormality. Subject's height were measured and regressed against their head circumference, facial breadth and facial height using a calibrated height rod, measuring tape and digital sliding caliper. Data collected were subjected to statistical analysis using MINITAB-18 data package. The results obtained showed that the mean height and standard deviation for both males and females were $163.9 \pm 12.9$ and 163.0 \pm 12.6 respectively, thus, Oro males are taller than females. A strong positive correlation was observed between height and head circumference, facial breadth and facial height in both males and females, with facial breadth having the strongest positive correlation with height for both genders. The model formulae (regression equation) for stature prediction of Oro males is $Y^{\prime}=4.6755+0.03609$ (facial breadth); for Oro females: $Y^{\prime}=4.7193+0.03225$ (facial breadth) and for both: $Y^{\prime}=4.6991+$ 0.03404 (facial breadth). It was concluded that facial breadth can be used to accurately estimate stature for the people of Oro tribe.
\end{abstract}

Keywords: Head circumference, Facial Breath, Facial Height, Stature prediction, Regression equation, Oro.

\section{INTRODUCTION}

$\mathrm{S}$ ature estimation is of immense important. It enables the anthropologists trace racial differences and variations, it helps the forensic practitioners solve medico-legal cases and the archaeologist carry out archaeological procedures which facilitates the process of sex, age and ancestry determination[1]. Body height derived from craniofacial dimension gives an indication on growth and development of an individual, exposing abnormality either in the shape or size of the cranial or facial region [2]. Bones of the cranium and face are very durable and easily recognizable part of the human skeleton. These makes them likely to survive postmortem taphonomic processes, thus, a complete biological profile could be deduce solely from the cranial and facial bone measurement to aid in the identification of an individual in cases of mass fatalities, where numerous persons were buried in a single burial pit or in cases of casualties involving multiple individuals with the same ancestry, sex or age. It provides a circumstantial identification, allowing the use of other methods for confirmation [3].A study of the Jatavs, measured the stature, nasal height and breadth, head height and breadth, and ear length found that there is a significant difference in the stature of Jatavs male from Jatavs female [4].The use of three head measurements- stature, head height and circumference and face height concluded that predicted body height are not different from actual body height [5].Using 150 subjects consisting of 107 males and 43 females ranging from 18 - 25 years, Tabrej et al. [6]concluded that estimation of body height from facial height is a supplementary approach when useful extremities sample and body part are not available for examination. Mansur et al. [7]reported that head circumference showed highly significant positive correlation with body height. A study on cephalic measurement to estimate stature on 300 subjects (150 males and 150 females) aged 18 - 25 concluded that stature could be estimated from crano-facial parameters using linear regression equation [8].Maxillofacial anthropometry in the form of head length and head breadth is a better predictor of stature if cephalofacial remains are brought for examination[1],[9],[10], [11], [12] [13], [14]. Using 14 different cephalofacial parameters, Agnihotriobserved that only three (facial breadth, head circumference, face length) emerged as major predictors of stature [15]. In the Nigerian population, the relationship between stature and cephalic dimensions found that cephalic dimensions correlated with stature and can be used to estimate stature when mutilated remains are brought for identification in Igbo ethnic group [16], in Ogoja local government area of Cross River State [17] and also in Ukwuani, Bini, Annang, Izon and Ikwere ethnic groups [18].

According to Krishan [19],the use of regression formulae derived in a specific population can under or overestimate stature when applied in another population; Hence, this study seeks to estimate the correlation between stature and craniofacial parameters and propose a model formula for stature estimation among the people of Oro ethnic group of Akwa Ibom State - Nigeria. 


\section{MATERIALS AND METHODS}

500 healthy subjects (245 males and 255 females) between the ages 18 and 77 without any physical abnormality were randomly selected for the study. Parameters measured include: Stature or Body height $(\mathrm{BH})$ - the vertical distance between the vertex and the plantar (heel) touching the floor measured using an anthropometric rod, Head Circumference (HC) - maximum circumference of the head measured from glabella to glabella with a measuring tape, passing over the opisthocranion, Facial Length (FL) - distance from the nasal root (nasion) to the lower border of the mandible measured using sliding caliper and Facial Breadth (FB) - straight distance from one zygomatic arch to the other on either side of the face measured using sliding caliper. Data collected were subjected to statistically analysis using MINITAB-18 data package for descriptive statistics of mean, standard deviation, maximum and minimum values, Pearson's correlation coefficient, Regression Analysis as well as graphic representation. All analysis was carried out gender-wise.

\section{RESULT}

The result of the mean and standard deviation of stature, head circumference, facial breadth and facial height of the Oro nation are shown in Table 1 . The mean and standard deviation of height of the males and females were 163.90 \pm 12.90 and $163.01 \pm 12.57$ respectively. This shows that Oro males had a significantly higher height than their female counterparts $(p<0.05)$. The mean and standard deviation of head circumference, facial breadth and facial height were $59.48 \pm 7.27,11.72 \pm 1.10$ and $12.78 \pm 6.32$ for males and $58.44 \pm 6.58,11.59 \pm 1.23$ and $12.32 \pm 1.07$ for females respectively. This Indicates a significantly larger facial dimension for males compared to females of Oro trbe $(\mathrm{p}<$ $0.01)$.

Table 2shows the Pearson correlation between the Height and head circumference, facial breadth and facial height of Oro nation and Figures 1- 6 show their scatter plot graphical representations. There was a positive correlation between their height and head circumference, facial breadth and facial height with different strengths, with female height versus facial breadth having the strongest positive correlation of $r=0.515$ while male height versus head circumference had the lowest but still moderately positive correlation of $\mathrm{r}=$ $0.434(p<0.01)$. The regression equation for Oro males, Oro females and both genders were also obtained.

TABLE 1: MEAN AND STANDARD DEVIATION OF MALE AND FEMALE PARAMETERS

\begin{tabular}{|l|l|l|}
\hline Parameters & Male & Female \\
\hline Totla Sample Size $(\mathrm{N})$ & 500 & 245 \\
\hline Sample Size (n) & 255 & $163.0 \pm 12.57$ \\
\hline Mean Height + Standard Deviation & $163.9 \pm 12.86$ & $58.44 \pm 6.58$ \\
\hline Mean head Circumference + Standard & $59.48 \pm 7.27$ & \\
\hline
\end{tabular}

\begin{tabular}{|l|l|l|}
\hline Deviation & & \\
\hline $\begin{array}{l}\text { Mean Facial Breadth + Standard } \\
\text { Deviation }\end{array}$ & $11.72 \pm 1.10$ & $11.59 \pm 1.23$ \\
\hline $\begin{array}{l}\text { Mean Facial Height + Standard } \\
\text { Deviation }\end{array}$ & $12.39 \pm 1.03$ & $12.32 \pm 1.07$ \\
\hline
\end{tabular}

$\mathrm{N}=$ Total Sample Size; $\mathrm{n}=$ Gender for Population

TABLE 2: PEARSON CORRELATION COEFFICIENTS (R) OF MALE AND FEMALE PARAMETERS

\begin{tabular}{|l|l|l|l|}
\hline $\begin{array}{l}\text { Pearsons Correlation } \\
\text { Coefficient (r) }\end{array}$ & Male & Female & P. value \\
\hline $\begin{array}{l}\text { Height vs Head } \\
\text { Circumference }\end{array}$ & 0.434 & 0.466 & $(\mathrm{p}<0.01)$ \\
\hline Height vs Facial Breadth & 0.509 & 0.515 & $(\mathrm{p}<0.01)$ \\
\hline Height vs Facial Height & 0.492 & 0.477 & $(\mathrm{p}<0.01)$ \\
\hline
\end{tabular}

\section{Regression Equations for Males}

Height versus head circumference

$\mathrm{Y}=\mathrm{A}+\mathrm{B}(\mathrm{C})$ where $\mathrm{A}$ and $\mathrm{B}$ are constants, and $\mathrm{C}$ the variable

Height $=\operatorname{Exp}\left(\mathrm{Y}^{\prime}\right)$

$\mathrm{Y}^{\prime}=4.8217+0.04657$ (Head Circumference)

Height versus Facial breadth

Height $=\operatorname{Exp}\left(\mathrm{Y}^{\prime}\right)$

$\mathrm{Y}^{\prime}=4.6755+0.03609 \quad$ (Facial Breadth)

Height versus facial height

Height $=\operatorname{Exp}\left(\mathrm{Y}^{\prime}\right)$

$\mathrm{Y}^{\prime}=4.6400+0.03701 \quad$ (Facial Height)

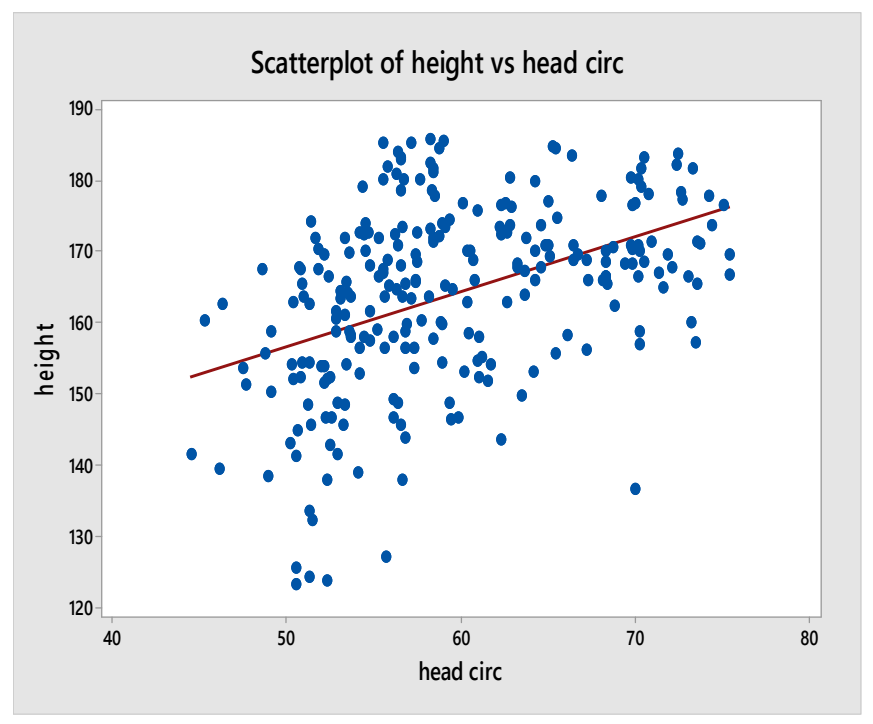

Figure 1: Scatterplot Graph of Height Vs Head Circumference for Males. Pearson correlation coefficient $(r)=0.434 \mathrm{P}<0.01$ 


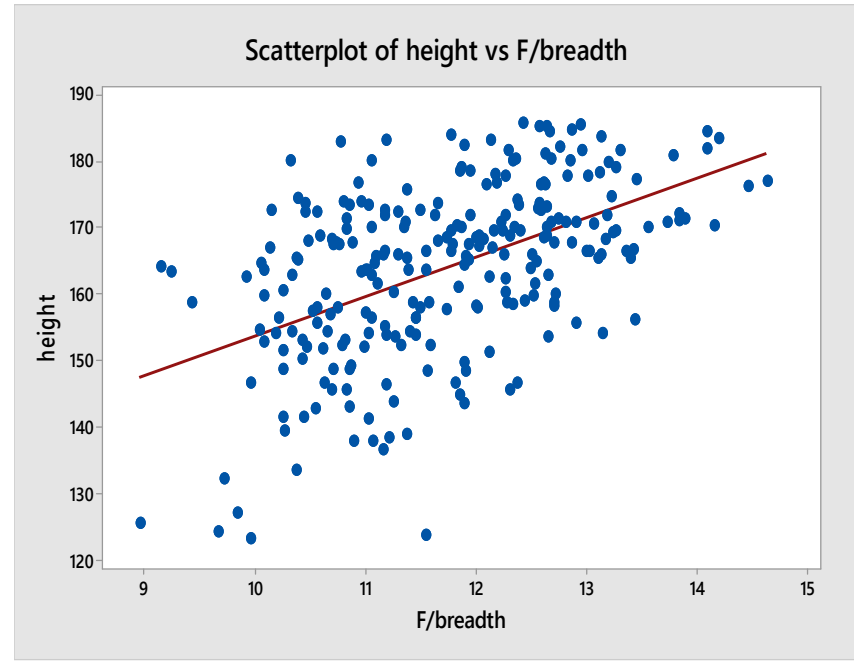

Figure 2: Scatterplot Graph of Height Vs Facial Breadth for Male.Pearson correlation coefficient $(\mathrm{r})=0.509 \mathrm{P}<0.01$

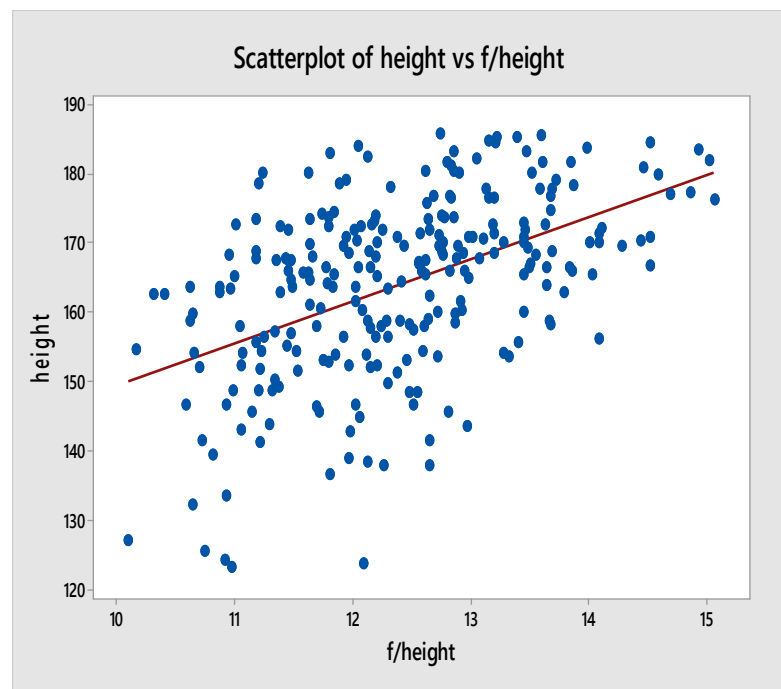

Figure 3: Scatterplot Graph of Height Vs Facial Height for Males.Pearson Correlation Coefficient $(\mathrm{r})=0.492 \mathrm{P}<0.01$

Poisson Regression Equations for Females

Height versus head circumference

$\mathrm{Y}=\mathrm{A}+\mathrm{B}(\mathrm{C})$ where $\mathrm{A}$ and $\mathrm{B}$ are constants, and $\mathrm{C}$ the variable

Height $=\operatorname{Exp}\left(\mathrm{Y}^{\prime}\right)$

$\mathrm{Y}^{\prime}=5.09340+0.000005$ (Head Circumference)

Height versus facial height

Height $=\operatorname{Exp}\left(Y^{\prime}\right)$

$\mathrm{Y}^{\prime}=4.6748+0.03390$ (Facial Height)

Height versus Facial breadth

Height $=\operatorname{Exp}\left(\mathrm{Y}^{\prime}\right)$

$\mathrm{Y}^{\prime}=4.7193+0.03225$ (Facial Breadth)

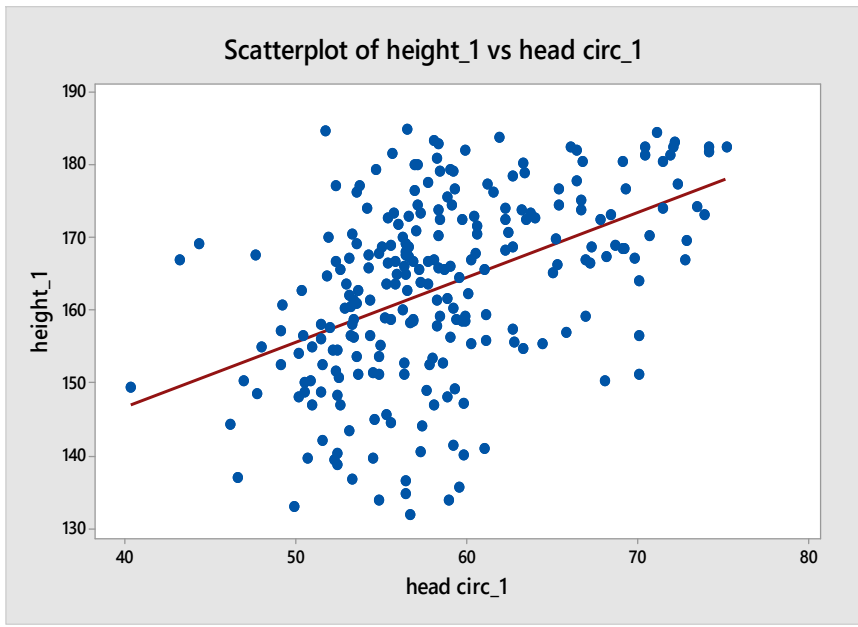

Figure 4: Scatterplot Graph of Height Vs Head Circumference For Female. Pearson Correlation Coefficient $(r)=0.466 \mathrm{P}<0.01$

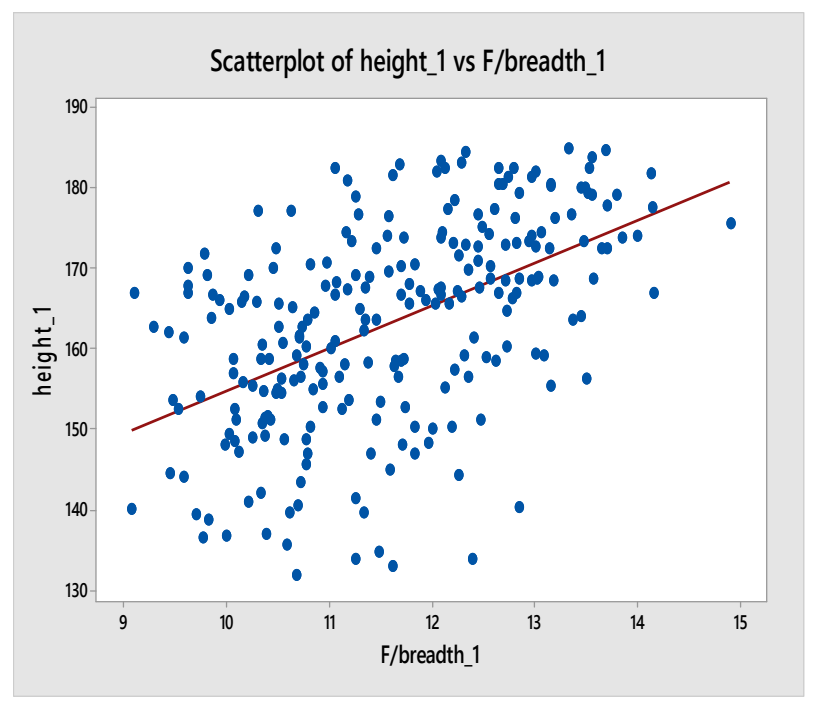

Figure 5: Scatterplot Graph of Height Vs Facial Breadth for Females. Pearson Correlation Coefficient $(r)=0.515 \mathrm{P}<0.01$

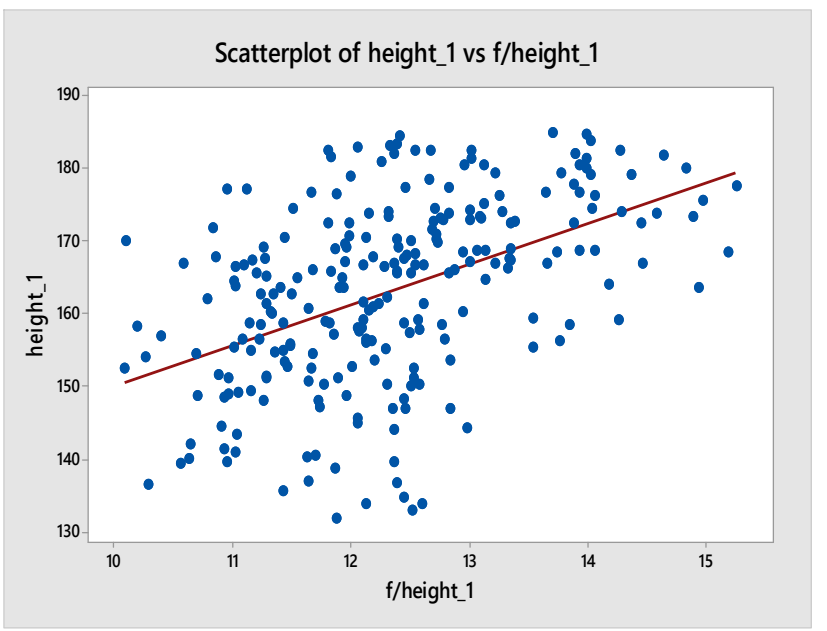

Figure 6: Scatterplot Graph of Height Vs Facial Height for Females. Pearson Correlation Coefficient $(r)=0.477 \mathrm{P}<0.01$ 


\section{Regression Equation for Oro tribe}

Height versus head circumference

$\mathrm{Y}=\mathrm{A}+\mathrm{B}(\mathrm{C})$ where $\mathrm{A}$ and $\mathrm{B}$ are constants, and $\mathrm{C}$ the variable

Height $=\exp \left(\mathrm{Y}^{\prime}\right)$

$\mathrm{Y}^{\prime}=4.8016+0.004992$ (head circumference)

Height versus facial breadth

Height $=\exp (\mathrm{Y})$

$Y^{\prime}=4.6991+0.03404$ (facial breadth)

Height versus facial height

Height $=\exp \left(\mathrm{Y}^{\prime}\right)$

$Y^{\prime}=4.6572+0.03549$ (facial height)

\section{DISCUSSION}

This study provides regression formulae for stature prediction using craniofacial measurements among the people of Oro in Akwa Ibom State of Nigeria. This proffers solution to the need for population specific formulae for stature estimation.

The mean height for Oro males $163.9 \pm 12.9$ and females $163.0 \pm 12.6$ indicatetaller Oro males compared to females. Tabrej et al., [6] obtained a mean height of $167.54 \pm 9.59$ for students of Hind Institute of Medical Sciences, India; indicating that this population are taller than people in Oro tribe.

The head circumference of $59.48 \pm 7.27$ for males and $58.44 \pm 6.58$ for females indicated that males have larger head circumference than females. Denis and Patrick [18]in their studyreported a higher mean height of 53.00 \pm 57.80 compared to females with $52.90 \pm 56.30$ among the Annangs. The association of $\mathrm{Y}$ chromosome with stature and the age of puberty being two years later in males gives extra time for growth [20], explaining why males are taller than females.

The mean facial breadth of $11.72 \pm 1.10$ for male and $11.59 \pm 1.23$ for females as well as facial height of $12.39 \pm 1.03$ male and $12.32 \pm 1.07$ for females indicates larger facial dimension for males compared to females. A study by Jibonkumar [21] on only males of Kabir, India showed a facial height of $11.25 \pm 0.44$. Agnihotriet al,[15] study showed a facial height of $11.58 \pm 0.71$ for males and $11.00 \pm 0.58$ for females in Indo-Mauritian population, further confirming the fact that males have a larger facial height than females, with Oro males showing larger facial height than Indians and IndoMauritian population.

Oro males were found to have a positive correlation of 0.434 for head circumference versus height while their females' counterparts had 0.466 positive correlations. Facial height was found to be 0.492 for males and 0.477 for females.
However, Agnihotri [15] in his findings obtained a positive correlation of 0.494 for males and 0.375 for females for head circumference; while facial height for male was found to be 0.328 and 0.164 for females.

The findings from this research indicate that craniofacial parameters can be used as important tool in forensic examination as they have positive correlation with stature and provide accuracy in the field of forensic anthropology.

\section{CONCLUSION}

This study has established that stature could be accurately predicted from craniofacial dimensions such as head circumference, facial height and facial breadth and concludes that facial breadth best predict stature for the people of Oro tribe.

\section{REFERENCES}

[1]. Singh, R. (2013). Estimation of Stature and Age from Head Dimensions in Indian Population. Int J Morphol31(4). 1185-1190.

[2]. Harper, C., Krill, J., Raven, S., and Jones, N. (1984). Intracranial Cavity Volumes. A New Method and its Potential Applications. Neuropathology Applied Neurobiology 10 (1): 25-32.

[3]. Richard, E. (2011). The Estimation of Stature from Measurement of the Isolated Cranium. Texas State University - San Marcos. Master of Art Thesis.

[4]. Sheetal, S. and Surinder, N. (2014). Estimation of Stature from Different Head and Face Measurement among Male and Female Jatavs of Delhi. Journal of Humanities and Social Sciences. University of Delhi, India: 19 (9): 52-55.

[5]. Agron, M. R. (2015). Predictor of Stature According to Three Head Measurements. Int. JMorphol. 33(3): 1151-1155.

[6]. Tabrej, A., Sanjay, S., Kamil, K., Saleba, S. and Arshad. (2017). Correlation between Facial Height and Body Height: A Prospective Anthropometric Study. Indian Journal of Clinical Anatomy and Physiology. 4(3):312-315.

[7]. Mansur, D. I., Haque, M. K., Sharma, K., Mehta, D. K. and Shakya, R. (2014). Use of head circumference as a predictor of height of an individual. Kathmandu University Med J.46(2): 8992.

[8]. Priti, N. K., Medha, A. and Amit, N. (2015). Regression Analysis on Stature Estimation from Cephalic Dimensions. Indian Journal of Basic and Applied Medical Research. 3: 298-312.

[9]. Swami, S., Kumar, M. and Patnaik, V. G. (2015). Estimation of Stature from Facial Anthropometric Measurement in 800 Adult Haryanvi Baniyas. International Journal of Basic and Applied Medical Sciences. ISSN: 2277-2103.

[10]. Wankhede et al., (2015). Estimation of Stature from Maxillofacial Anthropometry in a Central Indian Population. Journal of Forensic Dental Sciences4(1): 34-37.

[11]. Ebite, L. Ozoko T., and Oni A. (2008). Height: Ulna Ratio: A Method of Stature Estimation in Rural Community in Edo State, Nigeria. Journal Forensic Science 3:1-4.

[12]. Danbormo, B., Adebisi S. A. (2009). Estimation of height and weight from the lengths of second and fourth digits in Nigerians. Journal forensic science. 3:1-4.

[13]. Didia, B. C., Nduka, E. C., and Adele, O. (2009). Stature Estimation Formulae for Nigerians. Journal Forensic Science $54: 20-21$

[14]. Maina, N. B., Mahdi, O., and Kalayi, G. D. (2011). Sexual Dimorphism in Cranial Dimension among three Ethnic Groups of North-eastern Nigeria. AmericanJournal Science Index Research. 2:871-876

[15]. Agnihotri, A. K., Kachhwaha, S., Googooyle, K. and Allock, A. (2011). Estimation of stature from cephalofacial dimension by regression analysis in Indo-Mauritian Population. J Forensic, Legal Medicine. 18 (4): 166-72. 
[16]. Ukoha, U. U., Kosisochukwu, E. U., Onochie, O. U. and Lasbery, A. A. (2015). Estimation of Stature from Cephalic Dimensions in a Nigerian Population. Rev. Arg. Anat. Clin. 7(1): 17-25.

[17]. Lukpata, P. U., Ogan, C. A., Esomonu, U. G. and Tessy, E. D. (2016). Estimation of stature from some selected cephalofacial parameters among teenage indigenes of Ogoja local government area Cross River State. British Journal of Medicine and Medical Research. 12 (2): 1-7.

[18]. Eboh, D. E. and Patrick, S. I. (2017). Stature estimation from cephlaometric parameters of young adults in five Nigerian ethnic groups. Research article. Italian Journal of Anatomy and Embryology. 2: 98-109.
[19]. Krishan, K. (2008). Estimation of Stature from Cephalofacial Anthropometry in North Indian Population. American Journal of Physical Anthropology 181: 0379-0738.

[20]. Yamada, K., Ohta, M., and Hasekura, H. (1981). A Possible Association of YChromosome Heterochromatin with Stature. Human Genetic 58:268-270.

[21]. Jibonkumar. and Lilinchandra. (2006). Estimation of Stature Using Different Facial Measurements among the Kabui Naga of Imphal Valley, Manipur. Manipur University, Canchipur, Imphal India. 8(1): 1-3. 